\title{
Carbon dioxide and methane emissions from calcareous-marly rock under stress: experimental tests results
}

\author{
Giovanni Martinelli $\left({ }^{1}\right)$ and Paolo Plescia $\left({ }^{2}\right)$ \\ (') ARPA - Agenzia Regionale Prevenzione e Ambiente dell'Emilia-Romagna, \\ Sezione Provinciale di Reggio Emilia, Italy \\ $\left(^{2}\right)$ Istituto per lo Studio dei Materiali Nanostrutturati, ISMN-CNR, Montelibretti (RM), Italy
}

\begin{abstract}
The identified emissions of abiogenic carbon dioxide, carbon monoxide and methane are generally attributed to volcanic activity or to geochemical processes associated with thermometamorphic effects. In this paper we show another possible abiogenic source of emission, induced by mechanical, and not thermal, stresses. We investigated the mechanochemical production of carbon dioxide and methane when friction is applied to marly-type rock and studied the mechanisms determining the strong $\mathrm{CO}_{2}$ and $\mathrm{CH}_{4}$ emissions observed. A ring mill was used to apply friction and oriented pressure upon a synthetic calcite-clay mixture of varying proportions. We found that the $\mathrm{CO}_{2}$ and $\mathrm{CH}_{4}$ release versus the grinding action has a non-linear trend reflecting the behaviour of decreasing crystallinity, which indicates a close link between crystallinity and gas production. For the $\mathrm{CO}_{2}$ emission, we propose a release mechanism connected with the friction-induced fractures and the increase in structural disorders induced by creep in the lattice. The $\mathrm{CH}_{4}$ emission could be explained by a Sabatier reaction in which $\mathrm{CO}_{2}$ and hydrogen are involved to form $\mathrm{CH}_{4}$ and water.
\end{abstract}

Key words gas geochemistry - earthquake precursors - greenhouse gases

\section{Introduction}

Numerous studies on the natural sources of greenhouse gases, such as methane and carbon dioxide, have been carried out in relation to the evolution of the Earth atmosphere as well as in the fields of geological and geochemical research. Our primary interest lies in the effects of greenhouse gases on the global climate. It is well-known that the greenhouse gas balance is

Mailing address: Dr. Giovanni Martinelli, ARPA - Agenzia Regionale Prevenzione e Ambiente dell'Emilia-Romagna, Sezione Provinciale di Reggio Emilia, Via Amendola 2, 42100 Reggio Emilia, Italy; e-mail: giovanni.martinelli15@tin.it evaluated according to three major sources of emission: abiogenic (volcanoes or thermometamorphism); non-anthropogenic biogenic (vegetation, earth, oceans) and anthropogenic.

Inorganic $\mathrm{CO}_{2}$ emissions form a significant part of the total balance. The origin of this $\mathrm{CO}_{2}$ concentration is generally attributed to volcanoes, geochemical cycles and thermometamorphic degassing produced by contact between carbonates and magma. Thermometamorphic generation of $\mathrm{CO}_{2}$ has been discussed by Gianelli (1985), Marini and Chiodini (1994), Rogie et al. (2000), etc. Other greenhouse gases, such as abiogenic methane, are generally attributed to deep degassing.

Chiodini et al. (2000) estimated that thermometamorphic processes are responsible for about $36 \%$ of the $\mathrm{CO}_{2}$ measured in Central Italy, while $41 \%$ comes from deep sources and $23 \%$ is biological. 
Another interesting debate on the origin of greenhouse gases concerns the relationship between the greenhouse gas effect and the Cretaceous mass extinction. Many authors consider that the mass extinction of vertebrates at the end of the Cretaceous system was due to a meteorite impacting a carbonate basin; this induced the generation of enormous quantities of $\mathrm{CO}_{2}$ through the dissociation of carbonates as an effect of the shockwave (Ryder et al., 1996; MacLeod and Koeberl, 2001). However, the studies do not reach agreement on the mechanisms involved. Work on the carbonate compressibility by shockwaves shows how the $\mathrm{CO}_{2}$ dissociation threshold varies from 10 to $60 \mathrm{GPa}$ (Agrinier et al., 2001; Skála et al., 2001). According to other studies, carbonate dissociation could occur at much more limited pressures, but under certain stress conditions (Dickinson et al., 1991).

A recent work demonstrated the possibility of obtaining an intense $\mathrm{CO}_{2}$ emission from carbonate rocks with the contribution of mechanical energy by grinding alone (Martinelli and Plescia, 2004).

Methane is the subject of particular study, not only because of its environmental implications (greenhouse effect) but also in regard to its possible abiogenic origins of part of the oil reservoirs. A non-biogenic source of methane and more complex carbon composites could radically modify many of our current beliefs concerning the formation of oil and methane reservoirs (Beskrovny and Tikhomirov, 1968; Anders et al., 1973; Porfir'ev, 1974; Kropotkin and Valyaev, 1976, 1984; Kropotkin, 1985).

Another important reason for studying the production/emission mechanisms of carbon dioxide and methane is the monitoring and prediction of seismicity for which there is general agreement on the importance of endogenic derived gases as possible precursors (e.g., Irwin and Barnes, 1980; Geller, 1997; Toutain and Baubron, 1999).

The deformation processes that occurred in central Italy in 1997 and 1998 generated geochemical anomalies in the form of gas emissions and thermal springs within a $70 \mathrm{Km}$ radius of the epicentre (Heinicke et al., 2000; Favara et al., 2001; Italiano, 2001). These geochemical anomalies can be grouped together as an impressive degassing process due to the variations in crustal permeability generated by deformation.

To study the $\mathrm{CO}_{2} / \mathrm{CH}_{4}$ emission from dynamic compression, it has been necessary to use a system that can induce a large amount of fracturing through strong compression and friction and with energy sufficiently high as to reduce crystallinity, i.e., replicating what happens in rock during a strong tectonic activity.

\section{Experimental}

For laboratory work a ring mill was used, which is the most efficient grinding system available at present for the simulation of friction and mechanical compression over a large surface. Thanks to the mill we have (Martinelli and Plescia, 2004): a high exchange surface; high pressure on the materials; an isochemical ambient with controlled elementary exchange, and a high reaction rate.

The ring mill consists of a jar reinforced to contain the material and a grinding body (a steel ring and solid steel roller). A ring mill basically operates through non-hydrostatic compression (impact of the rings on the material particles) and friction (rotation forced by the grinding body on the particles and between the particles and the jar walls). Extremely high pressures can be achieved and complete amorphization of minerals with a Mohs hardness of less than 3-4 can be obtained within a few minutes (Plescia et al., 2003). The exchange surface is very high as the pulverized material has very high specific surfaces and the quantity of material placed in the mill can exceed $10 \mathrm{~g}$.

For our experimental trials we used a Labtech ESSA continuous ring mill conceived for continuous production of about $15 \mathrm{~kg} / \mathrm{h}$ and modified to accommodate diagnostic instruments (fig. 1), i.e., a konimeter to measure gas and dust and an analyzer for the internal temperature. Outside the grinding jar, a magnetic pickup connected to a digital oscilloscope provides data on the internal oscillations of the metallic mass, the grinding frequency and the dynamic events occurring during grinding (fig. 2).

The milled material consists of a mixture of pure calcium carbonate for analyses (Merck) 


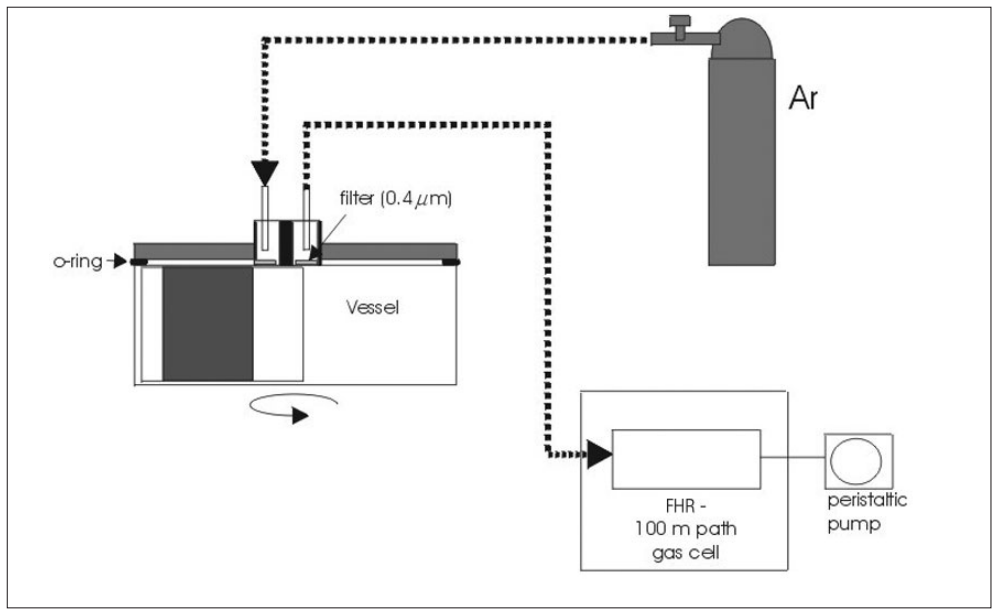

Fig. 1. Layout of experimental apparatus.

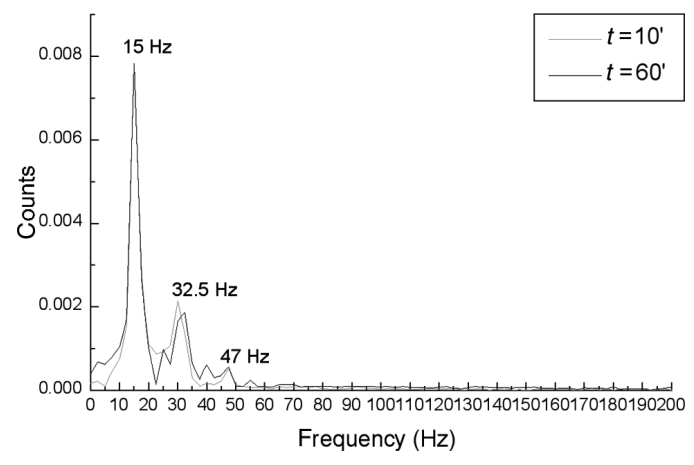

Fig. 2. Fourier analysis of mill impact frequencies ad different grinding times.

and kaolinitic clay. The clay sample, which was diffraction-analyzed before grinding, was found to be contaminated by quartz and a small quantity of illite.

Two types of tests were performed: for the first, non-stop grinding was carried out for 30 , 60,120 and $180 \mathrm{~min}$ on fixed amounts of $5 \mathrm{~g}$; for the second, fixed-time grinding for samples of $2,2.5,5,10 \mathrm{~g}$ was carried out.

The trials on samples of different grinding times and/or different weights allowed us to
Table I. Experimental conditions.

Grinding device: LABTECH ESSA

Jar material: steel

Grinding bodies: one $1 \mathrm{~kg}$ internal cylinder,

two $1.88 \mathrm{~kg}$ rings

Speed: $1200 \mathrm{rpm}$

FTIR - Gas cell experiment

FTIR: Nicolet Avatar 360

Sample cell: TGA thermostatic transfer line and «100 m» long path cell

Carrier gas: argon, $99.9 \%$ pro analysis

X-ray diffraction: Rigaku Rint 1200

Anode: $\mathrm{Cu}$, radiation $\mathrm{Cu} \mathrm{k} \alpha$

Monochromator: Graphite crystal

Power supply: $30 \mathrm{kV}-30 \mathrm{~mA}$

Differential thermal analyzer:

Stanton 1500 DTA-TGA simultaneous analyzer

Reference $\alpha$-Al2O 3

Ramp in air from 25 to $1000^{\circ} \mathrm{C}$ at $5 \%$ min

verify the effects of grinding with different amounts of energy per unit weight.

The mixtures were analyzed by TGA and DTA thermoanalyses to determine the amount of $\mathrm{CO}_{2}$ released, the temperature and the 
amount of energy utilized in dissociation. The mixtures had a $\mathrm{CO}_{2}$ content equal to $32 \%$ and an $\mathrm{OH}$ content equal to $6 \%$ (data obtained by differential thermal analysis).

We analyzed the gas using a FTIR spectrophotometer with «long path» thermostatic gas cells, similarly to what is used on GC/FTIR or TGA/FTIR systems. The instrument was a Nicolet Avatar 360. We used multiple acquisition software (Nicolet Omnic Series v.6.1A) to analyse the data in real-time and reproduce the reaction behavior. To analyze the gas in the jar and to avoid contamination from the outside, the jar was flushed with argon at a pressure of 1 bar. The gas flow was $0.5 / \mathrm{min}$, controlled by an analogue flowmeter. For the $x$-ray diffraction and thermoanalyses, we used, respectively, a Rigaku Rint 1200 diffractometer and a Stanton STA 1000 thermal balance (table I).

\section{Results}

Practically all the $\mathrm{CO}_{2}$ retained in marly rock was emitted in the grinding test. The quantity was slightly lower than that obtained by stoichiometry (about $20 \%$ as compared to the $22 \%$ obtained thermally), while methane, $\mathrm{CO}$ and $\mathrm{H}_{2} \mathrm{O}$ were emitted in measurable quantities.
The phenomenon was confirmed by realtime analysis of the gas formed during grinding (figs. 3 and 4).

Figures 3 and 4 show the behaviour of the FTIR spectra in the vibration region of $\mathrm{CO}_{2}$, methane and vapor as a function of grinding time for sample of a fixed weight. We can see that the $\mathrm{CO}_{2}$ emission curve shows a complex behavior. There is a rapid increase at the beginning of the phenomenon, followed by a progressive decrease. During the experiment, the first two minutes are blank analyses, with the mill off, and no anomalous emission observed. The $\mathrm{CO}_{2}$ emission effect is marked by peaks superimposed at a continuous level, while the methane appears after prolonged treatment, together with water (fig. 3).

Figure 5a,b shows a notable difference between thermal curves of the treated and as-is samples. The latter show three main reactions: weight loss due to evaporation of interstitial water $\left(100-120^{\circ} \mathrm{C}\right)$; weight loss from dehydroxylation of clay, between $450-550^{\circ} \mathrm{C}$, and weight loss related to the dissociation of $\mathrm{CO}_{2}$ from calcite, between 700 and $900^{\circ} \mathrm{C}$.

After grinding, the dehydroxylation peak, characteristic of the crystalline phase of clay, disappears; the dissociation peak of $\mathrm{CO}_{2}$ decreases until it nearly disappears, from $35 \%$ for the as-is samples to $6 \%$ of the $180^{\prime}$ grinding
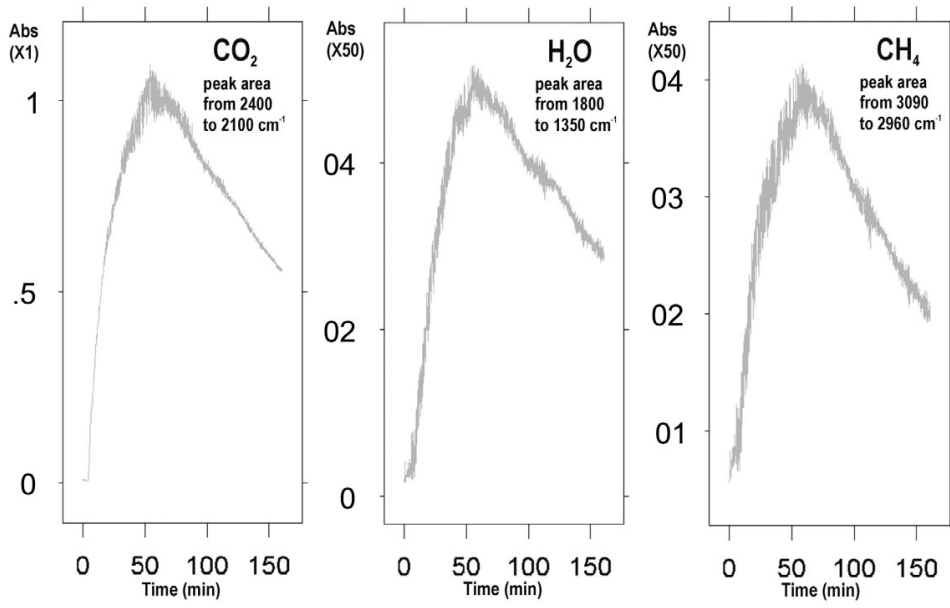

Fig. 3. FTIR Gas analysis: $\mathrm{CO}_{2}, \mathrm{H}_{2} \mathrm{O}, \mathrm{CH}_{4}$ emissions during milling (1 g sample, 180 min grinding). 




Fig. 4. $3 \mathrm{D}$ view of FTIR spectra (1 g sample).

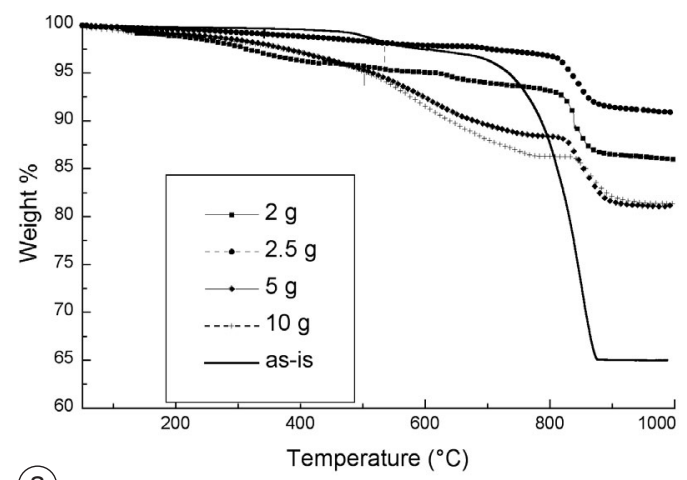

(a)

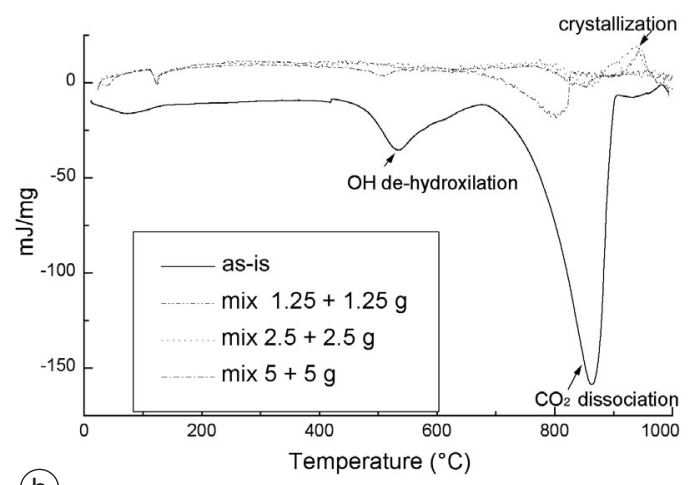

(b)

Fig. 5a,b. Thermal analysis of ground samples: a) TGA analysis; b) differential thermal analysis.

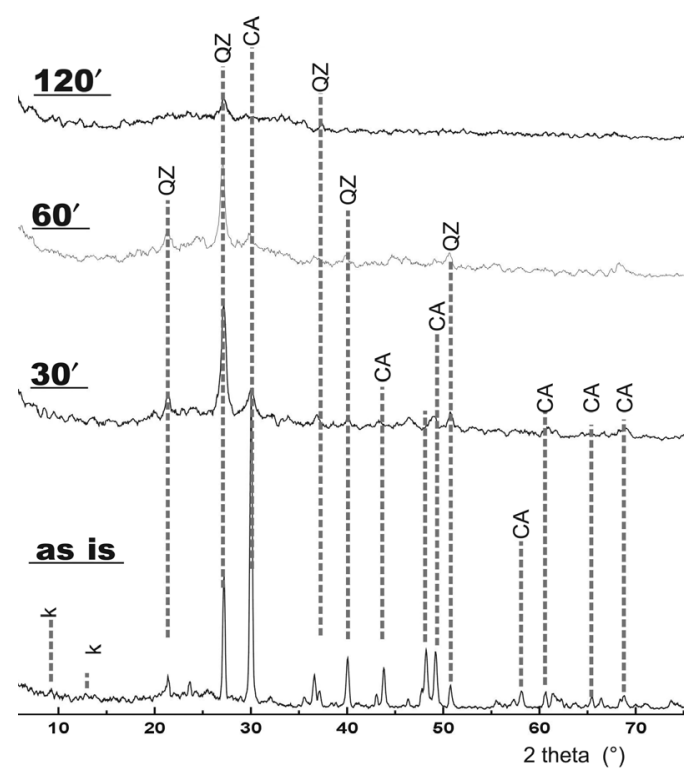

Fig. 6. XRD analysis of treated samples at different main grinding time phases: QZ - quartz; $\mathrm{k}$ - kaolinite; CA - calcite.

samples, and a crystallization peak appears at very low temperatures. The vitrification temperature, for a mixture calcite/kaolinite clay as is, is around $1300-1400^{\circ} \mathrm{C}$.

In the grinded samples this temperature is placed at $1100^{\circ} \mathrm{C}$. Figure 6 shows the $x$-ray diffraction analysis of grinded samples at different grinding times. The XRD shows how the treatment leads to amorphization of the calcite and clay minerals. In particular, calcite tends to amorphous product, instead of crystallize as aragonite, as observed in previous experiments on calcite single crystal grinding (Martinelli and Plescia, 2004).

In the $120^{\prime}$ sample, it can be observed only the main reflections of quartz, which constitutes the hardest phase of the mixture.

\section{Discussion of results}

The most noteworthy data are related to the modality and typology of emission, which can 
be attributed to the mechanical, and not the thermal, phenomenon imposed on the marly material.

Worth noting, firstly of all, are the $\mathrm{CO}_{2}$ emissions, which we have explained in terms of two parallel mechanisms: burst emissions, due to the release of $\mathrm{CO}_{2}$ molecules from fresh grinding-induced fractures; and continuous emissions, deriving from the bulk, i.e., produced by the material which is not yet fractured, but is undergoing compression and micro-cracking (plastic deformation, slippage of planes).

Burst emissions seem to be prevalent only during the very early grinding phases, while continuous emissions become dominant after a few minutes' treatment. The phenomenon of continuous $\mathrm{CO}_{2}$ emission brings us to conclude that the deformed lattice of the carbonate releases $\mathrm{CO}_{2}$ up to equilibrium. Instead water and methane emissions originate in a different scenario. In fact, we suggest that the methane and water derive from the Sabatier reaction

$$
\mathrm{CO}_{2}+4 \mathrm{H}_{2} \rightarrow \mathrm{CH}_{4}+2 \mathrm{H}_{2} \mathrm{O} \text {. }
$$

This reaction is moderately exothermic, $\mathrm{H}^{\circ}=-165 \mathrm{~kJ} / \mathrm{mol}$, and could originate when hydrogen molecules become available during grinding. The protonization event coincides with dehydroxylation of the clay during the grinding of the mixture. Several authors (Aglietti et al., 1986; Plescia et al., 2003) have clearly demonstrated that phyllosilicates are particularly sensitive to the mechanochemical action, which easily leads to the elimination of the $\mathrm{OH}$ groups and to a completely amorphous structure. It is also well-known that clays, particularly kaolinite, are capable of exchanging protons with the external ambient, but only half of the available protons are exchangeable with a simple high- $p H$ reaction, while acid or neutral $p H$ exchange is not viable.

The phenomenon could evolve as follows: during the first grinding phase (or friction action), the material is fractured and the calcium carbonate releases carbon dioxide with spot emission; then, the $\mathrm{CO}_{2}$ emission becomes abundant and continuous, while the chemical ambient becomes strongly alkaline; the clays are destroyed by grinding and lose hydroxyls and, hence, protons, some of which recombine with $\mathrm{CO}_{2}$ molecules to give rise to methane and water - both observable in the FTIR gas spectra; at the end of the grinding, the $\mathrm{CO}_{2}$ emission tends to very slowly decrease up to re-equilibrium of the material.

To verify our hypothesis, the role of energy during grinding needs to be carefully evaluated. By using the mathematical model developed to study the ring mills (Plescia, 2003), we calculated that the energy provided by the mill is about $1240 \mathrm{~kJ} / \mathrm{h}(345 \mathrm{~J} / \mathrm{s})$. This energy is subdivided by the amount of material put in the mill. The energy generated would be sufficient to complete the reaction, and the chemical ambient is alkaline enough to guarantee de-protonization of the clay.

It is also worthwhile recalling a particular mineralogical fact: in some minerals present in certain metapelites, such as cordierite, significant quantities of hydrocarbons derived from methane were revealed by IR (Mottana et al., 1983; Khomenko and Langer, 1999). The presence of methane and related hydrocarbons could be associated with gas formation during metamorphic events.

\section{Conclusions}

The data obtained so far allow us to put forward the following hypotheses: in addition to the known mechanisms involved in $\mathrm{CO}_{2}$ and methane production, there exists a natural mechanism that works through a mechanochemical-type phenomenon; an abundant amount of $\mathrm{CO}_{2}$ is produced during shear stress by mechanochemical molecular dissociation of calcium carbonate; the energies involved are sufficient to dissociate carbonate, so long as there is a very high grinding body/material ratio; the amount of shear stress necessary to obtain the dissociation of $\mathrm{CO}_{2}$ and production of $\mathrm{CH}_{4}$ is less then $4 \mathrm{kbar}$, the threshold value to obtain the crystallization of aragonite.

The phenomenon observed in the laboratory could be tentatively extrapolated to a much larger scale so as to give us some idea of what actually happens when carbonate-rock mass undergoes tectonic activity. 


\section{REFERENCES}

Aglietti, F., P.J.M. Lopez and E. Pereira (1986): Mechanochemical effects in kaolinite grinding, Int. $J$. Min. Proc., 16, 135-146.

Agrinier, P., S.R. Boyd, I. Martinez, U. Scharer, M. JAVOY and A. DEUTSCH (2001): On the kinetics of $\mathrm{CaO}+\mathrm{CO}_{2}^{--}>\mathrm{CaCO}_{3}$ and $\mathrm{CO}_{2}$ released during impact processes, Ann. Geophysicae, 13 (suppl. III) C738 (abstract).

Anders, E., R. HAYATSu and M.H. Studier (1973): Organic compounds in meteorites, Science, 182, 781-790.

Beskrovny, N.S. and N.I. TikHOMIROV (1968): Bitumens in the hydrothermal deposits of Transbaykal, in The Genesis of Oil and Gas (Nedra Press, Moscow), pp.

Chiodini, G., F. Frondini, C. Cardellini, F. Parello and L. Peruzzi (2000): Rate of diffuse carbon dioxide Earth degassing estimated from carbon balance of regional aquifers: the case of Central Apennine, Italy, $J$. Geophys. Res., 105, 8423-8434.

Dickinson, J.T., L.C. Jensen, S.C. LANGFord, P.E. RosenMBERG and D.L. BLANCHARD (1991): $\mathrm{CO}_{2}$ emission accompanying the fracture of calcite, Phys. Chem. Minerals, 18, 320-325.

FAVARA, R., F. ItAliano and G. Martinelli (2001): Earthquake-induced chemical changes in the thermal waters of the Umbria Region during the 1997-1998 seismic swarm, Terra Nova, 13 (3), 227-233.

GELLER, R.J. (1997): Earthquake prediction: a critical review, Geophys. J. Int., 131, 425-450.

GianELLI, G. (1985): On the origin of geothermal $\mathrm{CO}_{2}$ by metamorphic processes, Boll. Soc. Geol. It., 104, 575-584.

Heinicke, J., F. Italiano, V. Lapenna, G. Martinelli and P.M. NucCiO (2000): Coseismic geochemical variations in some gas emissions of Umbria Region (Central Italy), Phys. Chem. Earth, 25, 289-293.

IRWIN, W.P. and I. BARNES (1980): Tectonic relations of carbon dioxide discharges and earthquakes, J. Geophys. Res., 85, 3115-3121.

Italiano, F., G. Martinelli and P.M. Nuccio (2001): Anomalies of mantle-derived helium during the 19971998 seismic swarm of Umbria-Marche, Italy, Geophys. Res. Lett., 28, 839-842.

KHOMENKo, V.M. and K. LANGER (1999): Aliphatic hydrocarbons in structural channels of cordierite: a first evidence from polarized single-crystal IR absorption spectroscopy, Am. Min., 84, 1181-1185.
KropotKin, P.N. (1985): Degassing of the Earth and the origin of hydrocarbons, Int.. Geol. Rev., 23, 12611275 .

KropotKin, P.N. and B.M. VALAEV (1976): Development of a theory of deep-seated (inorganic and mixed) origin of hydrocarbons (Goryuchie Iskopaemye: problemy geologii i geokhimii naftidov i bituminoznykh porod), edited by N.B. VASSOEVICH, Akad. Nauk SSR, 133-144 (in Russian).

MacLeod, K.G. and C. Koeberl (Editors) (2001): Catastrophic events and mass extinctions: impacts and beyond, Geol. Soc. Am. Spec. Pap. 356, pp. 749.

MARINI, L. and G. ChIOdini (1994): The role of $\mathrm{CO}_{2}$ in the carbonate-evaporite geothermal systems of Tuscany and Latium, Italy, Acta Vulcanol., 5, 95-104.

Martinelli, G. and P. Plescia (2004): Mechanochemical dissociation of calcium carbonate: laboratory data and relation to natural emissions of $\mathrm{CO}_{2}$, Phys. Earth Planet. Int., 142 (3/4), 205-214.

Mottana, A., A. Fusi, B. Bianchi Potenza, R. Crespi and G. LiBORIO (1983): Hydrocarbon bearing Cordierite from the Derivo Colico road tunnel (Como, Italy), Neues Jahrb. Mineral. Abh., 148, 181-191.

Plescia, P., D. Gizzi, S. Benedetti, L. Camilucci, C. FANizZA and F. PAGLIETTI (2003): Mechanochemical treatment to recycling asbestos containing waste, Waste Management, 23, 209-218.

PorfiR'Ev, V.B. (1974): Inorganic origin of petroleum, Am. Assoc. Petrol. Geol. Bull., 58, 3-33.

Rogie, J.D., D.M. Kerrick, G. Chiodini and F. Frondini (2000): Flux measurements of non-volcanic $\mathrm{CO}_{2}$ emission from some vents in Central Italy, J. Geophys. Res., 105, 8435-8445.

RYdER, G., D. FASTOWSKY and S. GARTNER (Editors) (1996): The Cretaceous-Tertiary event and other catastrophes in Earth history, Geol. Soc. Am. Spec. Pap. 307, pp. 576

SkÁla, R., J. Ederová, P. MATE`JKA and F. Hörz (2001): Mineralogical studies of experimentally shocked dolomite: implications for the outgassing of carbonates, in Catastrophic Events and Mass Extinctions: Impacts and Beyond, edited by MACLEOD K.G. and C. Koeberl, Geol. Soc. Am. Spec. Pap. $356,571-585$

ToutAin, J.P. and J.C. BAubron (1999): Gas geochemistry and seismotectonics: a review, Tectonophysics, 301, 1-27. 